\title{
Advances in photosynthesis and respiration
}

\author{
Including bioenergy and related processes: a new look beginning \\ with volume 35
}

\author{
Thomas D. Sharkey
}

(C) Springer Science+Business Media B.V. 2012

Five years ago Govindjee announced the publication of Volumes 24 and 25 in the series Advances in Photosynthesis and Respiration [Govindjee (2006) Photosynthesis Research 90:91-96]. Since 1994, the "Advances..." series of photosynthesis books have provided a comprehensive resource for the photosynthesis community. This series was inspired by the three-volume (I, 1945; II, Part 1, 1951; and II, Part 2, 1956) set Photosynthesis and Related Processes, written by Eugene I. Rabinowitch. Rabinowitch began his project in 1938 and finished it in 1956. By 1994 it was clear that the comprehensive treatment of topics in photosynthesis was an ongoing need and at the same time it would be impossible for one person to write it all or even edit one or a few volumes that would claim to cover all of photosynthesis. Govindjee initiated the idea of a comprehensive series of books that cover the process of photosynthesis from femtosecond to an entire season; he took on the task of Series Editor, inviting and cajoling the world's experts to serve as editors for volumes that now number 34 . Volume 34 has been appropriately dedicated by Julian Eaton-Rye, Baishnab C. Tripathy and myself (Thomas D. Sharkey) to Govindjee for his self-less service to the Photosynthesis Community at large. I joined as Series Co-Editor since volume 31 . The authors and volume editors are a world-class group of experts in photosynthesis. As you read this, Volume 34 is now available and the last details of producing Volume 35, Genomics of Chloroplasts

T. D. Sharkey $(\square)$

Michigan State University, 410 Biochemistry Building,

East Lansing, MI 48824, USA

e-mail: tsharkey@msu.edu and Mitochondria edited by Ralph Bock and Volker Knoop will have been finished and the volume will also be available. For volume 34, see http://www.springerlink. com/content/978-94-007-1578-3/contents/.

With volume 35 we are making some changes to keep the books a leading source of information on photosynthesis and related energy processes. The series title is updated to include a subtitle so that it is now ADVANCES in Photosynthesis and RespiRation Including Bioenergy and Related Processes. This broader title reflects the growing importance of bioenergy as one of the societal needs that photosynthesis research addresses (photosynthesis provides food, fuel, and fiber for human existence). We have a few inquiries about a bioenergy volume but strongly encourage interested people to contact either me (tsharkey@msu.edu) or Govindjee (gov@illinois.edu).

The front cover, which had a distinctive white background and color palette up to volume 34 has been changed to a webfriendly green background (Fig. 1). The graphic expression of the topics in each volume, which had been a major component of the front cover will move inside. Readers may also see that the past few volumes have had significantly more color and the color figures are now better integrated into the chapters, instead of being collected in one section of the book. This improvement was possible because of changes in how the books are produced. Another change is that references to chapters in books will be tracked by bibliographic services. This will help authors provide evidence of the importance of their work. We anticipate that these changes in the books in this series will enhance the importance of edited volumes in the dissemination of the science of photosynthesis and bioenergy.

The series publisher, Springer, now makes the table of contents and front matter of all of the volumes available online (http://www.springerlink.com/content/1572-0233/books/ 
Advances in Photosynthesis and Respiration

Photosynthesis

Plastid Biology, Energy Conversion and Carbon Assimilation

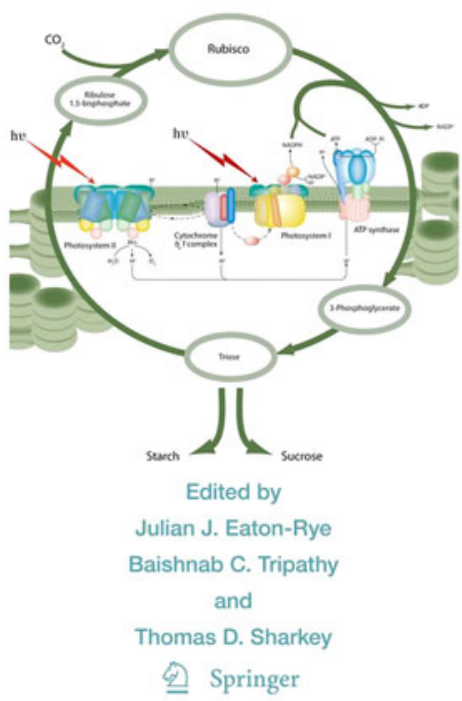

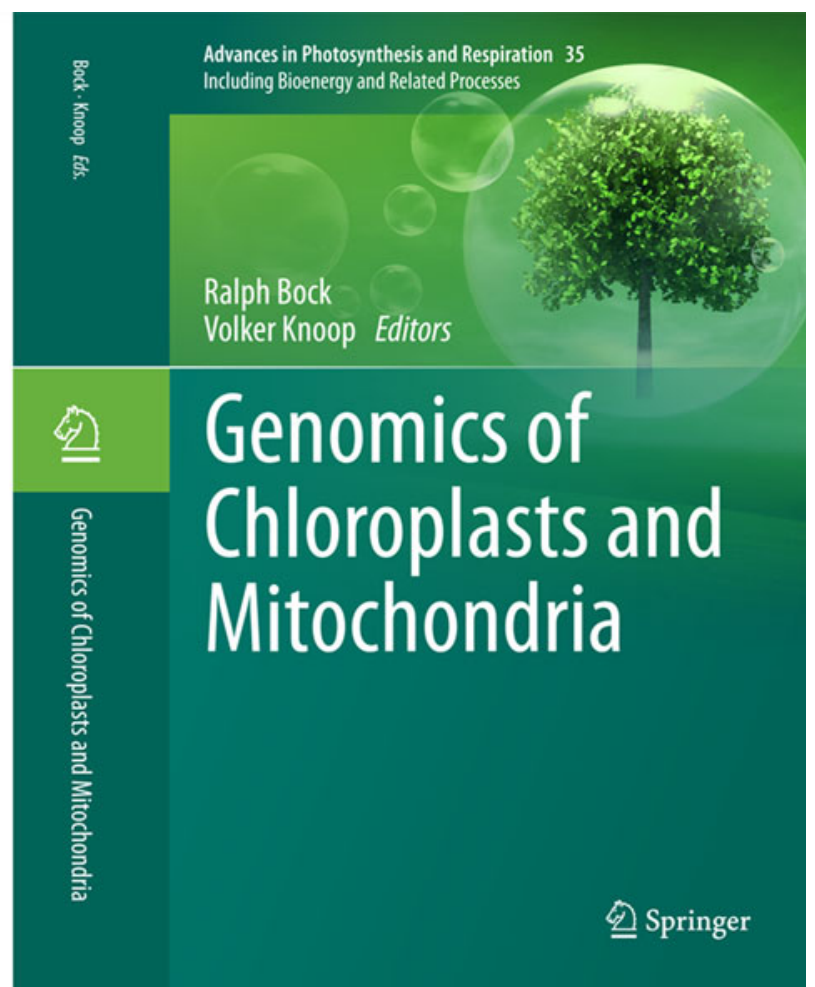

same with each volume and could represent the interesting ideas about photosynthesis that bubble up from the chapters in each volume. The large font for the title is intended to make it easy to read when the cover is presented as a small icon on a web site see also http://www.springer.com/series/5599); the front matter is downloadable free by all. It is anticipated that the web access will become the predominant method by which people access these books and many enhancements are underway to improve the web experience. Many university libraries have bought electronic access to all volumes. If you do not have full access from your university consider writing to your librarian so that you can get access and use the books. They are intended to be effective teaching tools and the university-wide access will allow you to assign readings from these volumes in your courses.

Readers are encouraged to watch for the publication of the forthcoming books (not necessarily arranged in the order of future appearance):

- Chloroplast biogenesis: during leaf development and senescence (Editors: Basanti Biswal, Karin Krupinska and Udaya Chand Biswal).

- The structural basis of biological energy generation (Editor: Martin Hohmann-Marriott).

- Photosynthesis in bryophytes and early land plants (Editors: David T. Hanson and Steven K. Rice).
- Canopy photosynthesis: from basics to applications (Editors: Kouki Hikosaka, Ülo Niinemets and Niels P.R. Anten).

- Microbial bioenergy: hydrogen production (Editors: Davide Zannoni and Roberto De Philippis).

In addition to the above contracted books, the following topics are under consideration (we request the readers to send suggestions, of possible new topics, and of possible editors and authors of the following, to me or Govindjee):

- Algae, cyanobacteria: biofuel and bioenergy.

- Artificial photosynthesis.

- ATP Synthase and proton translocation.

- Bacterial respiration II.

- Carotenoids II.

- Cyanobacteria II.

- (The) Cytochromes.

- Ecophysiology.

- Evolution of photosynthesis.

- FACE Experiments.

- Global aspects of photosynthesis.

- Green bacteria and heliobacteria. 
- Interactions between photosynthesis and other metabolic processes.

- Limits of photosynthesis: where do we go from here.

- Photosynthesis, biomass, and bioenergy.

- Photosynthesis under abiotic and biotic stress.

- Plant respiration II.

The Consulting Editors of Advances in Photosynthesis and Respiration Series are, in alphabetical order: Elizabeth Ainsworth (USA), Basanti Biswal (India), Robert E. Blankenship (USA), Ralph Bock (Germany), Julian EatonRye (New Zealand), Wayne Frasch (USA), Johannes
Messinger (Sweden), Masahiro Sugiura (Japan), Davide Zannni (Italy), and Lixin Zhang (China). In view of inclusion of "Bioenergy and Related Processes" to the title of our Series, we seek suggestions of names of scientists who may be suitable for the future Board of Consulting Editors.

Govindjee and I thank all who have served as editors or authors and hope that photosynthesis research will benefit for many years because of the community effort to document Advances in Photosynthesis and RespiRation Including Bioenergy and Related Processes. 